\title{
REAL-TIME ISOHUME MAPPING FOR COOL AND WARM HUMIDITY ISLES OF BENGALURU CITY
}

\author{
Rajesh Gopinath $^{1 *}$, S. Sachin ${ }^{2}$, Ajay Singh ${ }^{2}$, Harendra \\ Prasad $^{2}$, S. Neha ${ }^{2}$
}

\begin{abstract}
Key-words: Bengaluru, Islands, Moisture, Thermal, Urban.
A naturally gifted city, the development of Urban Moisture Islands (UMI) in Bengaluru is disheartening owing to its rampant-unplanned urbanization to satisfy its rapidly prevalent population. The subsequent increase in built-up area, consequent loss of productive agricultural lands/green zones, encroachment of surface water bodies coupled with the ill-preparedness of decision makers to handle the expansion have invariably impacted the micro-climate of the city. In this present research, an attempt has been made to detect the development of Urban Moisture Islands in Bengaluru by conducting real-time survey at 100 observatories marked across the entire urban locations; with thermo-hygrometers as per the W.M.O. guidelines. The study confirmed the violation of the Human Thermal Comfort Range in 61, 3, 36, 62, 32 and 14 stations during the monitoring for $6 \mathrm{AM}, 9 \mathrm{AM}, 12 \mathrm{PM}, 3 \mathrm{PM}, 6 \mathrm{PM}$ and 9 PM respectively. The major causative factors for this drastic climatic transformation from the once sobriquet climate is due to the elevated greenhouse gas emissions, gradual loss of green cover, steady replacement of natural surfaces with materials that have higher thermal properties.
\end{abstract}

\section{Introduction}

Prevalent urbanization and rampant industrialization have resulted in the modification of local city climate; essentially altering the local humidity profile to produce drier environs, often referred to as the "Urban Moisture Islands" (UMI). Essentially its intensity is identified to be the differences between rural and urban humidity (Kuttler Wilhelm, 2007). The contributor influencing this distribution is mainly due to loss of the natural heat sinks inherent to the topography.

Altered vapor-pressure values not only influence the formation of the Urban Radiation Fog (Sachweh M. and Koepke P., 1995) and development of

1 Faculty, Department of Civil Engineering, BMS Institute of Technology and Management, Bengaluru 64, India, dr.rajeshgopinathnair@gmail.com

${ }^{2}$ Department of Construction Technology and Management, AcIT, Bengaluru 107, India 
photochemical smog (Rubio M.A. et al. 2002); but also behave as an important control parameter for the human energy balance and thermal comfort (Mayer H., 1993). The city of Bengaluru has been victim of rampant urbanization and this growth has resulted in the deterioration of environmental conditions; as industrialization, population growth and urbanization have reinforced each other (Rajesh Gopinath et al., 2017). This directly determines the loss of more heat sinks and sources of evaporative surfaces. The ability to hence manage the Urban Humidity Islands and to also simultaneously preserve the natural environment is therefore a matter of key concern.

\section{Literature Review}

Only a few studies have been written about the urban influence on atmospheric humidity. In a study carried out for finding the horizontal structure of the heat and moisture islands of the Pune city, the results indicated that, at night, the central parts of the city appeared as both heat and moisture islands whereas at sunrise, as heat and dry islands (Vrishali, Deosthali, 2000). In a study carried out in Germany, it was found that the urban site was more humid in $31.4 \%$ of the cases investigated and was only rarely significantly more humid in 4.6\% (Kuttler Wilhelm, 2007). Though the above cited undertaken researches have individually investigated humidity variations, and postulated guidelines and remedial measures; none of them has though managed to cover a vast area and thereby they fail with real-time applications; and hence this study attempts to further investigate on them.

\section{Experimental Methodology}

The key objectives of the present research primarily involved a comparison of the Relative Humidity Levels among the various monitoring observation stations, and secondly, it identified the observation points where the values of the Human Thermal Comfort Factor have been exceeded, by further determining the intensity of Urban Moisture Islands, followed by the subsequent plotting of the isohumes over the entire Bengaluru city. To accomplish the aforementioned objectives, at first, a thorough site-selection process was carried out to identify more than one hundred potential stations with distinct land-use categories, which could produce representative results. This was achieved through a 'Supervised Classification' for land-use pattern by a combination of field work, analysis, aerial photography and personal survey. The entire Bengaluru town area was taken into consideration for this survey, consequently encompassing both its rural, urban and sub-urban areas. Figure 1 provides an overview of the entire study area, pointing all the 100 observation stations. Secondly, regular measurements of Relative Humidity were made 
simultaneously at all stations on weekdays and week-ends at 6 AM, 9 AM, 12 PM, 3 PM, 6 PM and 9 PM, for a period of 1 year to encompass all seasons and especially summer. Data of rainy days were rejected. However, due to financially imposed restrictions and time constraints, the monitoring activity did not span over the entire day and was restricted to a 3 hours interval instead.

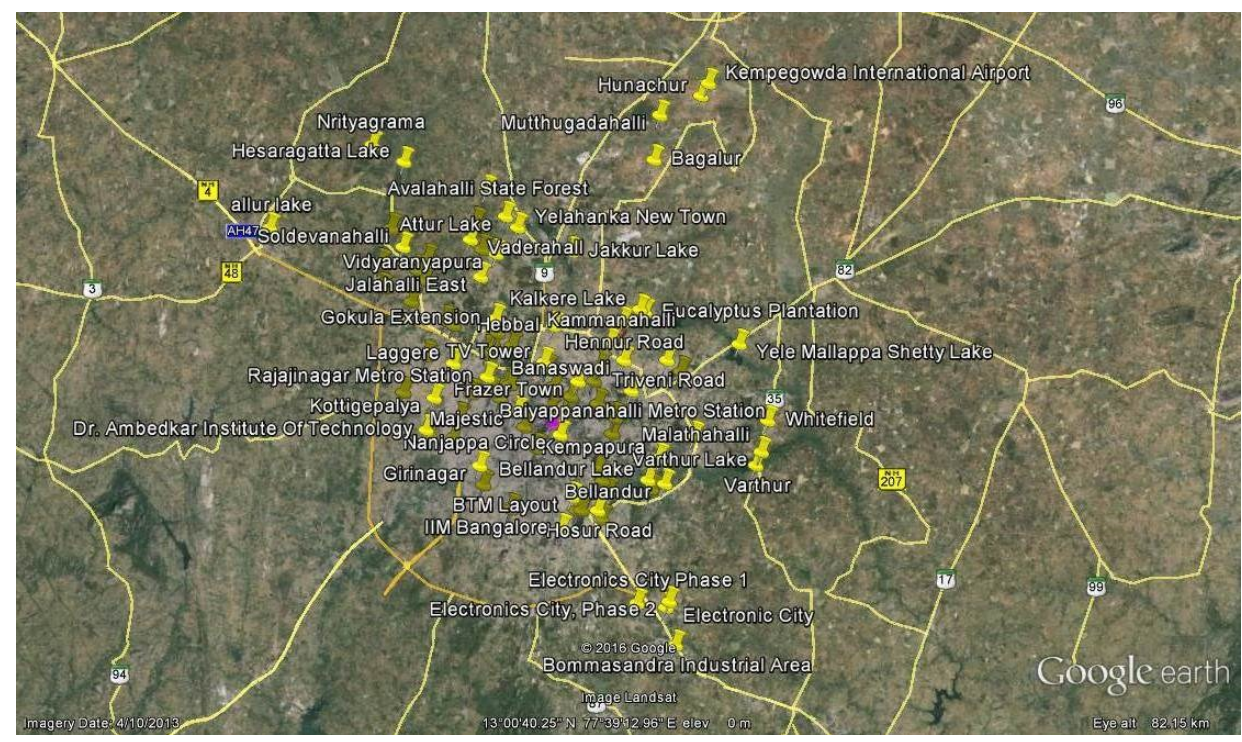

Fig.1. Google Image of Bengaluru City, highlighting the Geographical Location of the 100 observation stations.

On each day, a "Reference Station" was monitored to ensure data normalization. The monitoring activity was in concordance with WMO guidelines (T.R Oke, 2006). The monitoring activity was carried out with the aid of calibrated and synchronized high precision portable digital ThermoHygrometers. Further, the Climatic Data Analysis and Representation process involved plotting and drawing inferences about the temporal behavior of the selected parameters across all observation stations. This was actually done by calculating and consequently drawing the iso-hume lines from the normalized daily data, which aided in projecting color coded mapping for any violation w.r.t human thermal comfort. The intensity of the Urban Moisture Islands (U.M.I.) was calculated by subtracting the relative humidity values across all stations from the Reference Station 'value' for each monitoring period by applying Equation 1; where ' $i$ ' represents the respective hour of observation. 


$$
\Delta \mathrm{RH}=\mathrm{RH}_{\text {urban }} \text { i }^{\mathrm{i}} \mathrm{RH}_{\text {reference }}{ }^{\mathrm{i}}
$$

Eq. 1

\section{Results And Discussions}

The simultaneous monitoring activity at each observation station has revealed several startling facts. On a generic note, the following daily observations have been drawn. Firstly, for most of the time, all urbanized station values have constantly kept higher than the Reference Station values, while at those stations with natural landscape, the actual values were lower than the Reference Station ones. Also, while all stations exposed similar trends in this respect, certain stations recorded higher values than others.

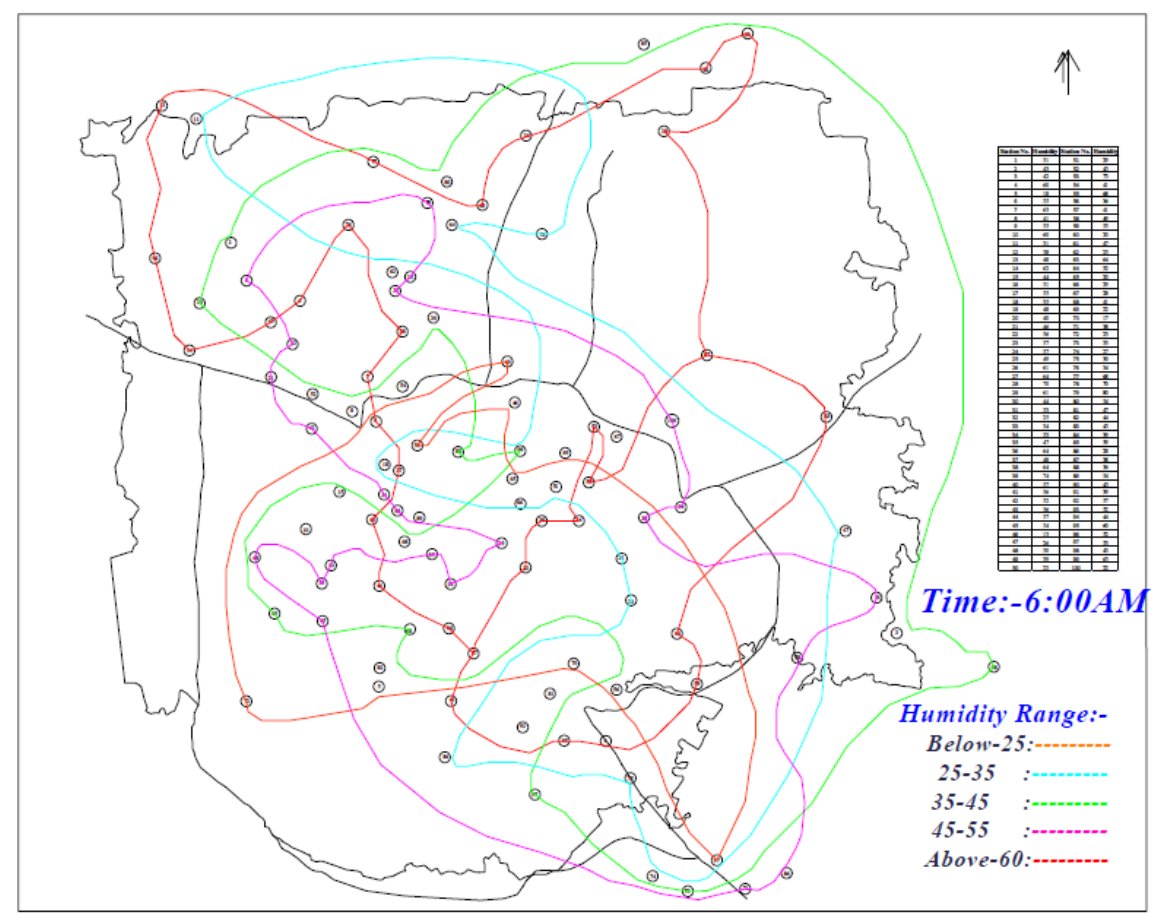

Fig.2. 6 AM Isohumes for Bengaluru.

For stations with sufficient heat sinks, the maximum Relative Humidity values were usually observed at 6 AM, and the Minimum Relative Humidity ones were recorded around $3 \mathrm{PM}$. However, for stations with more heat sources, the Minimum Relative Humidity values were generally observed at 9 AM. Based on generic observations, before mid-day, stations were found to have 
higher values than the Reference Station ones, and in the after-noon, they exposed lower values. Most of the time, the observation stations had lower values than the Reference Station ones before noon (12 PM) but from 12 PM onwards, the values have increased. Also, while most stations presented similar trends till $12 \mathrm{PM}$, after that hour onwards, the values were fluctuating in highly erratic patterns. As can be observed from Figure 2, several intra-humidity islands become pretty clear within the study area, showcasing different violations of the Human Thermal Comfort Range.

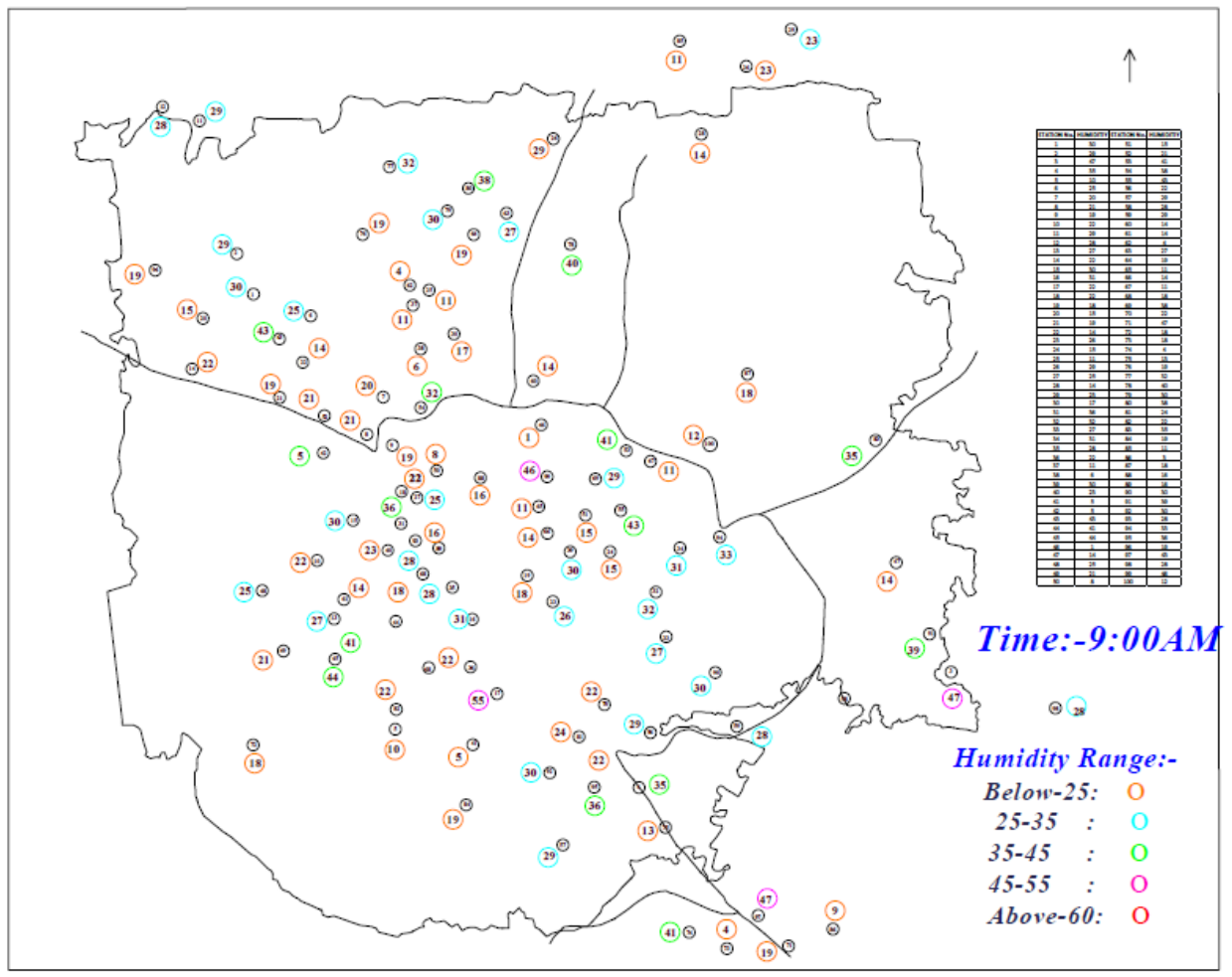

Fig.3. 9 AM Isohumes for Bengaluru.

During the observation hour of $6 \mathrm{AM}$, the maximum UMI intensity was observed in densely populated areas and these higher levels can mainly be attributed to anthropogenic heat emissions from the AC ducts of the commercial enclaves and $\mathrm{AC}$ vehicles. The minimum UMI intensity was found in the locations with a large water-body cover. In total, the values in over 61 stations have violated the Human Thermal Comfort Range during the monitoring period. 
During the 9 AM observations (Figure 3), the maximum UMI intensity corresponded to two densely populated locations with large glass-covered wall areas and many AC ducts. Again, the stations with large areas covered by lake waters surfaces exposed minimum intensities. There were only 3 violations during this mid-morning monitoring period.

At the 12 PM monitoring period (Figure 4), the maximum UMI intensity was reached at a metro station, due to the anthropogenic heat emissions from the AC locomotive/installations. The minimum intensity values for this time were found at two geographically separated stations that had some lake reservoirs nearby. 36 violations of the Human Thermal Comfort were found during this monitoring hour.

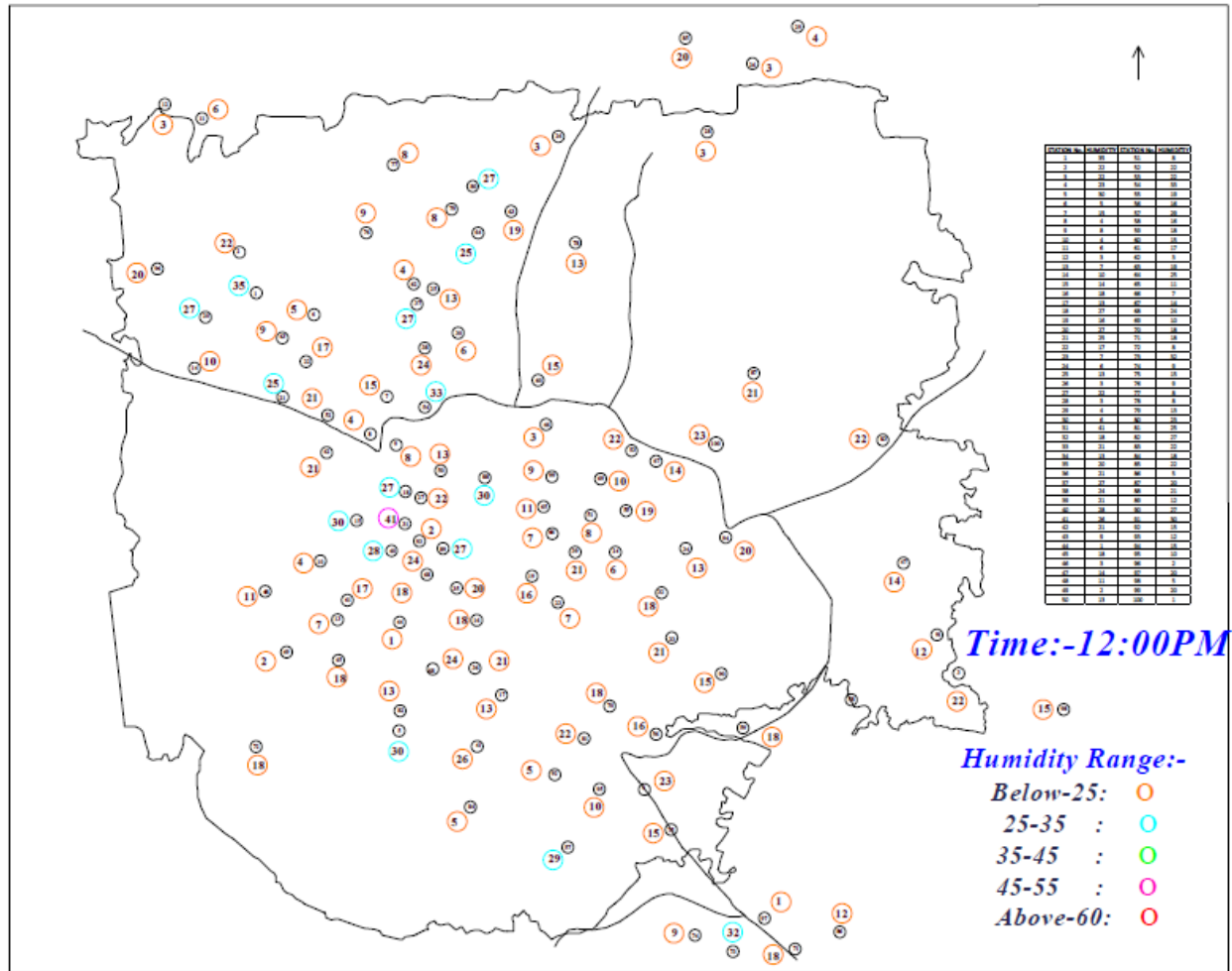

Fig.4. 12 PM Isohumes for Bengaluru.

During the 3 PM monitoring hour (Figure 5), the maximum intensity was identified at two stations that were densely populated and exposed higher levels of anthropogenic heat emission from the $\mathrm{AC}$ ducts of the commercial enclaves 
and $\mathrm{AC}$ vehicles. The minimum intensity was found at two stations with waterbodies in the surrounding areas. Unlike other towns and cities, Bengaluru has a system of artificial/man-made lakes and no rivers. Though, Bengaluru was once popularly known as 'The Region of a thousand Tanks', currently, most of these lakes have fallen prey to urbanization (Fathima Samana S. and Rajesh Gopinath, 2012). This directly indicates the loss of more heatsinks and sources of evaporative surfaces. As Figure 5 showcases, there were 62 violations recorded in total during this monitoring hour.

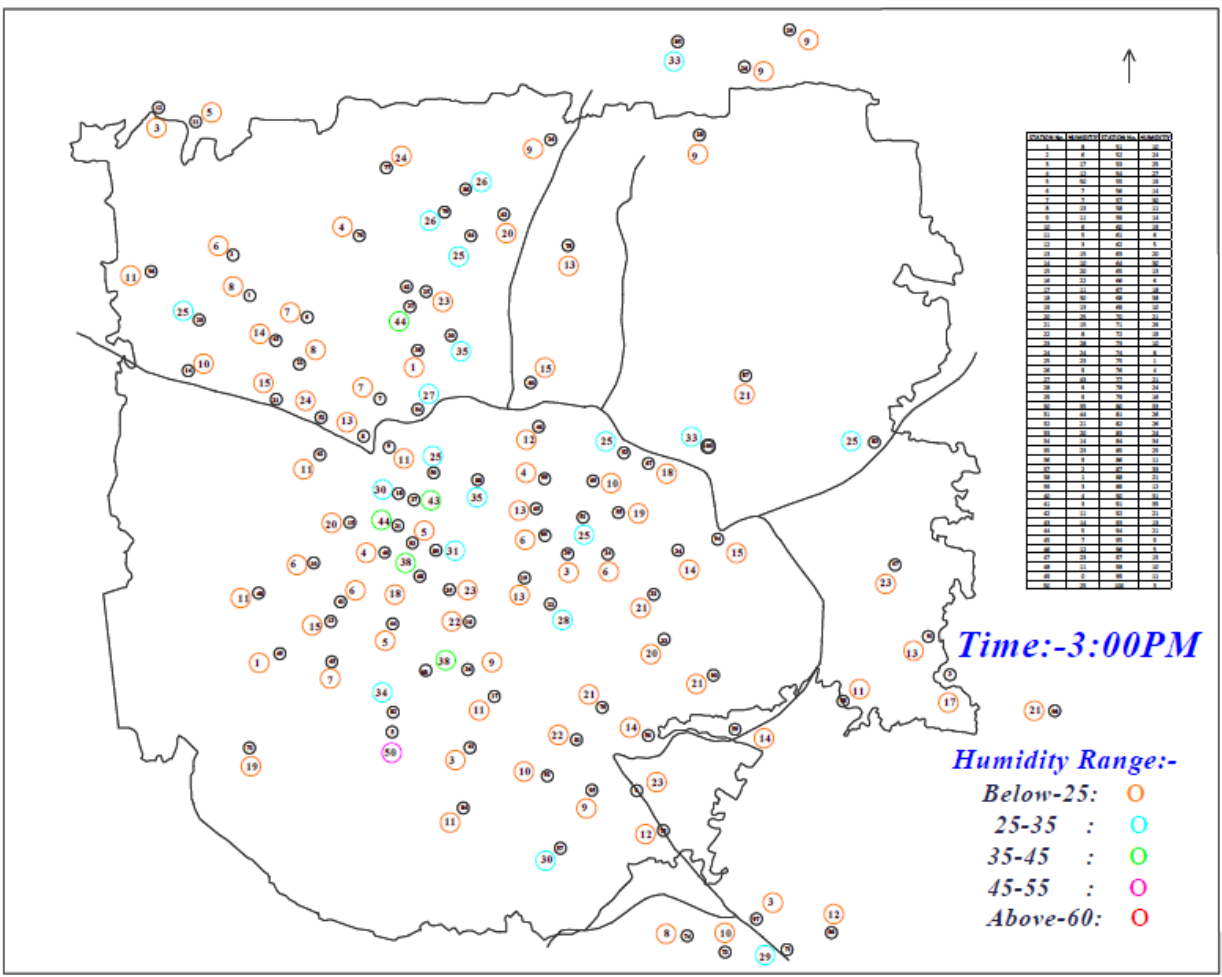

Fig.5. 3 PM Isohumes for Bengaluru.

During the 6 PM monitoring hour (Figure 6), the maximum UMI intensity values were recorded in two prime industrial locations. As the world's $4^{\text {th }}$ best technology hub after Boston, London and California, Bengaluru city is now home to over 650 Multi-National Companies, at the cost of more green-cover land being utilized for establishing industries (Rajesh Gopinath et al., 2015). 
All this inherently meant that immense heat plumes were released from each industry production unit, consequently diminishing water content in the air. The minimum UMI intensity values were found in two locations owing to the presence of extensive lake-cover and moderate green-cover areas, respectively. Presently, today, these open-air spaces are fast dwindling because the artificial surfaces of glass and concrete structures have largely increased. This is also most evident from the fact that corresponding UMI values at about 32 stations have eventually violated the Human Thermal Comfort because of the absence of adequate green spaces.

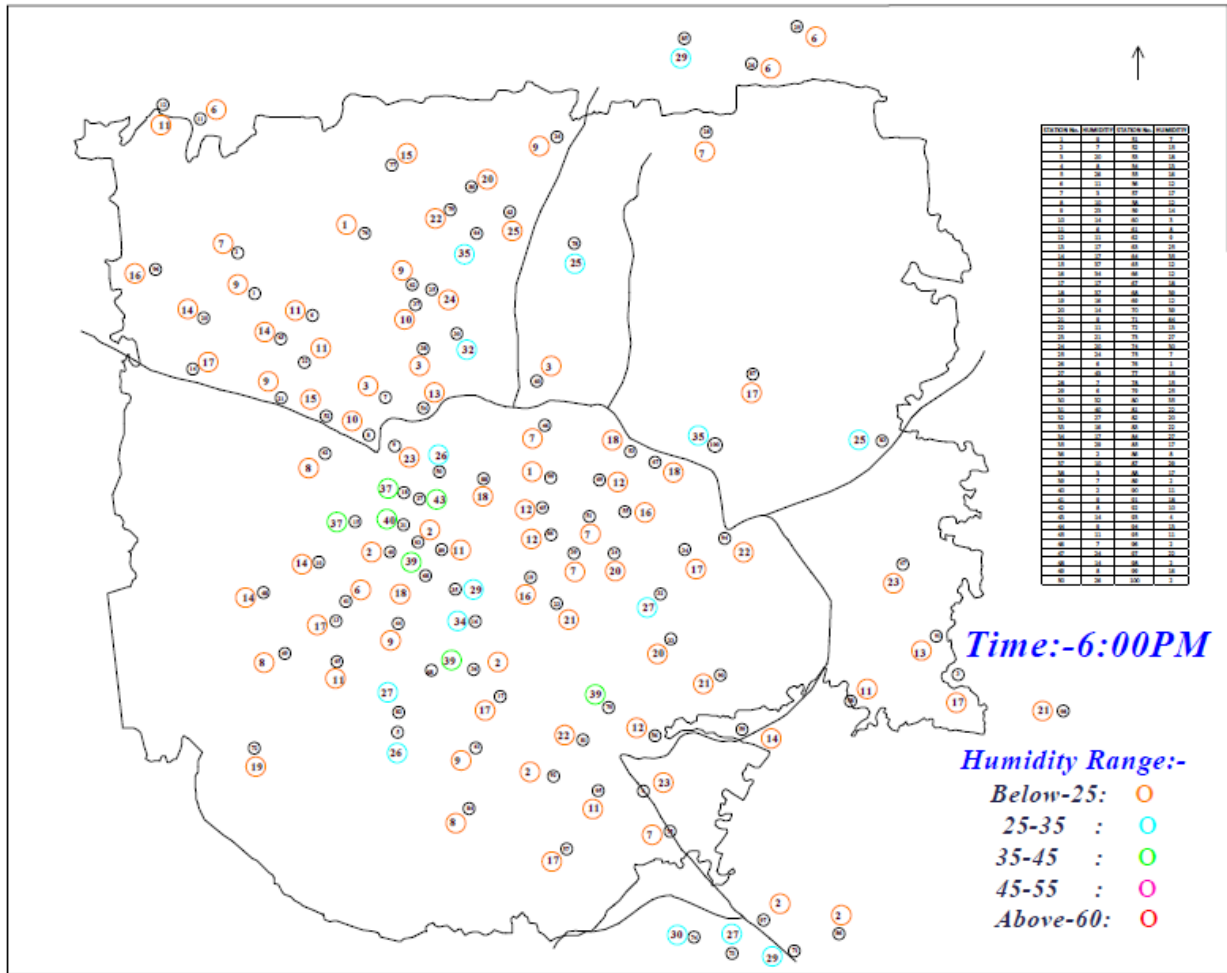

Fig.6. 6 PM Isohumes for Bengaluru.

During the 9 PM monitoring hour (Figure 7), the maximum UMI intensity values recorded in two locations were mainly due to car exhausts released in a very from their densely populated and heavily trafficked areas. In this respect, it is important to know that Bengaluru has the highest share of 2-wheelers, cars, cabs, autos, buses and goods vehicles out of all the other cities in Karnataka 
state (Yateen Lokesh et al., 2017). The minimum UMI intensity was found in an observation station lying by the banks of some adjoining lakes. In total, 14 stations have exceeded the Human Thermal Comfort values during this time. The factors influencing the distribution of urban humidity values include the combined influences of active layer roughness, moisture sources and thermal fields; hence and consequently the absolute humidity is sometimes higher at night in the urban areas than in the rural areas, as highlighted on the plot.

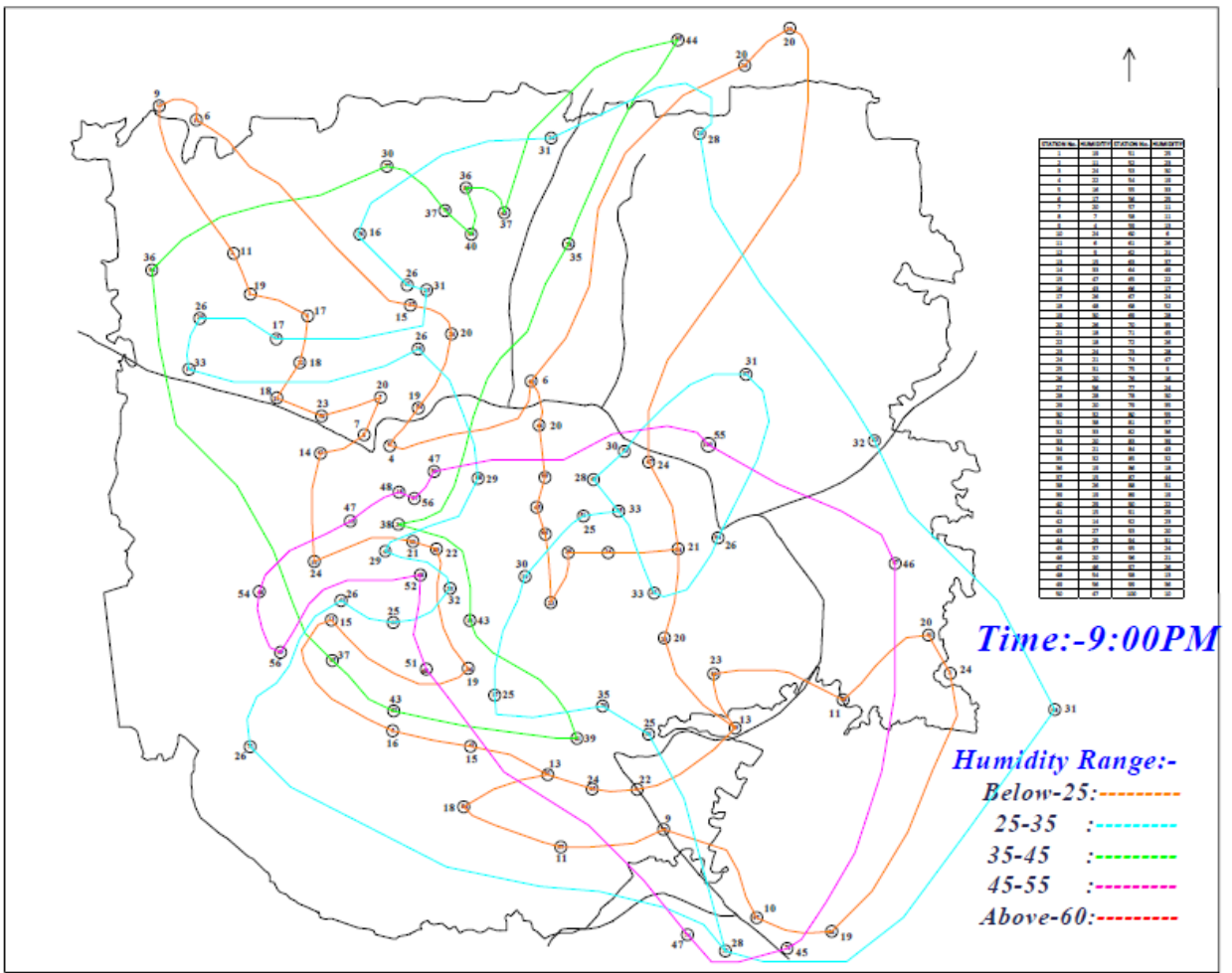

Fig.7. 9 PM Isohumes for Bengaluru.

Overall, one may observe that the major factors contributing to these humidity differences and creation of several Urban Moisture Islands can be due not only to elevated greenhouse gas emissions from AC ducts and car exhausts in the form of water-vapor and carbon dioxide, but also to the gradual loss of Bengaluru's urban green-cover which directly impedes cooling processes and prevents natural evapotranspiration processes by shading natural surfaces from direct sunlight, on one hand, and by altering heat and water exchanges between 
the ground layer and the atmosphere, as increasing parts of the city are being covered by artificial materials with great impermeability, low albedo and higher thermal properties, thus absorbing considerable heat during the day and releasing it back into the atmosphere at night, consequently enhancing the urban heat moisture effect.

Hence, we may infer that the contrast between the urban and the 'undisturbed' climates is basically due to the heat and moisture exchange fluxes between the ground layer and the upper air environment, and that its momentum is significantly enhanced by the urban landscape, which brought about great changes to the natural landscapes, by reducing the green-cover areas, by shrinking the water-bodies surfaces and by using on a large scale of artificial concrete and glass wall and street areas (Vijayalakshmi, A., Gopinath, R., Bhanumurthy, P.R., 2014). Obviously, all these are directly or indirectly related to the ongoing urbanization process, a global phenomenon to which Bengaluru town has immensely succumbed to.

\section{Conclusions}

The major focus of this research was to identify the Urban Moisture Islands created in Bengaluru town area and to understand the major factors contributing to these humidity differences. Despite being a naturally gifted city, the development of the Urban Moisture Islands in Bengaluru city is mainly due to the rampant urbanization process and unplanned scheme of urban geometry constructions, to satisfy the populations sporadically growing in all directions. The study confirms the violation of the Human Thermal Comfort range of 25-60 $\%$ in $61,3,36,62,32$ and 14 observation stations during the monitoring hours at: $6 \mathrm{AM}, 9 \mathrm{AM}, 12 \mathrm{PM}, 3 \mathrm{PM}, 6 \mathrm{PM}$ and 9 PM respectively. The causative factors mainly refer to elevated greenhouse gas emissions, gradual loss of Bengaluru's urban green-cover and steady replacement of natural surfaces.

\section{References:}

1. Fathima Samana S, Rajesh Gopinath, 2012, Tracing the Impact of Bangalore's Urbanisation on its wetlands with a case study of Sampangi Lake, International Journal of Environment, Ecology, Family and Urban Studies, 2 (4), 23-28 p.

2. Kuttler Wilhelm, 2007, Urban/Rural Atmospheric Water Vapor Pressure Differences and Urban Moisture Excess in Krefeld, Germany, Int. J. Climatol, 27, 2005-2015 p. https://doi.org/10.1002/joc. 1558 
3. Mayer H., 1993, Urban Bioclimatology, Experientia, 49, 957-963 p. https://doi.org/10.1007/BF02125642

4. P.R. Bhanumurthy, Rajesh Gopinath, Vijayalakshmi Akella, 2014, Comparison studies in Land-cover Mapping Analysis, International Journal of Emerging Technologies in Computational and Applied Sciences, 8 (6), 499-503 p.

5. Rajesh Gopinath et al., 2017, Real-Time Thermal Mapping for Heat and Cool Archipelagos of Bengaluru, India, Civil and Environmental Engineering, 13 (2), 106-111 p, DOI: 10.1515/cee-2017-0014.

6. Rajesh Gopinath, Vijayalakshmi Akella, P.R. Bhanumurthy, 2015, Parametric study of heat island effect due to urban sprawl in Bangalore, $\mathrm{PhD}$ Thesis, Jawaharlal Nehru Technological University, Anantapuram, http://hdl.handle.net/10603/46778.

7. Rubio M.A., Lissi E., Villena G., 2002, Nitrite in Rain and Dew in Santiago City, Chile. Its Possible Impact on the Early Morning Starts of the Photochemical Smog, Atmospheric Environment, 36, 293-299 p. https://doi.org/10.1016/S13522310(01)00356-9

8. Sachweh M., Koepke P., 1995, Radiation Fog and Urban Climate, Geophysical Research Letters, 22 (9), 1073-1076 p. https://doi.org/10.1029/95GL00907

9. T.R Oke, 2006, Guide To Meteorological Instruments and Methods of Observation, Switzerland: Secretariat Of The World Meteorological Organization, Chapter 1, 1$22 \mathrm{p}$.

10. Yateen Lokesh, Rajesh Gopinath et al., 2017, Real Time Noise Violation Mapping from Road Traffic Network for Entire Bangalore City, Bulletin of Civil Engineers, , 60 (1), 177-181 p., Saint-Petersburg, Russia, ISSN 1999-5571.

11. Vijayalakshmi, A., Gopinath, R., Bhanumurthy, P.R., 2014, Distinguishing between Global Warming and Urban Warming for Bangalore with the aid of Statistical Analysis, American International Journal of Research in Science, Technology, Engineering \& Mathematics, 6 (1), 57-60 p.

12. Vrishali, Deosthali, 2000, Impact of Rapid Urban Growth on Heat and Moisture Islands in Pune City, India, Atmospheric Environment, 34, 2745-2754 p. https://doi.org/10.1016/S1352-2310(99)00370-2

C 2020 by the authors. Licensee UAIC, Iasi, Romania. This article is an open access article distributed under the terms and conditions of the Creative Commons Attribution (CC BY-NC-ND) license (https:// creativecommons.org/licenses/by-nc-nd/4.0). 